\title{
Öğrenci Projelerinin Genellenebilirlik Kuramı ile İncelenmesi
}

\author{
Durmuş Özbaş $1^{1}$, Serdar Arcagök ${ }^{2}$
}

${ }^{1}$ Eğitim Bilimleri Bölümü, Eğitim Fakültesi, Çanakkale Onsekiz Mart Üniversitesi, Çanakkale, Türkiye, dozbasi@gmail.com ${ }^{2}$ Temel Eğitim Bölümü, Eğitim Fakültesi, Çanakkale Onsekiz Mart Üniversitesi, Çanakkale, Türkiye, serdararcagok21@,comu.edu.tr

\section{Sorumlu Yazar: Durmuş Özbaşı}

Makale Türü: Araştırma Makalesi

Kaynak Gösterimi: Özbaşı, D. \& Arcagök, S. (2021). Öğrenci projelerinin genellenebilirlik kuramı ile incelenmesi. Ĕ̆itimde Kuram ve Uygulama, 17(2), 69-78. doi: 10.17244/eku.1024532

Etik Not: Araştırma ve yayın etiğine uyulmuştur. Bu çalışmada veriler 2020 yılı öncesi toplanmış olup, veri toplama sürecinde katılımcıların gönüllü katılımı gözetilmiştir.

\section{Examining Student Projects with Generalizability Theory}

Durmuş Özbaş $1^{1}$, Serdar Arcagök ${ }^{2}$

${ }^{1}$ Departmens of Educational Sciences, Faculty of Education, Çanakkale Onsekiz Mart Üniversitesi, Çanakkale, Turkey, dozbasi@gmail.com

${ }^{2}$ Departments of Primary Education, Faculty of Education, Çanakkale Onsekiz Mart Üniversitesi, Çanakkale, Turkey, serdar_arcagok21@,comu.edu.tr

Corresponding Author: Durmuş Özbaşı

Article Type: Research Article

To Cite This Article: Özbaşı, D. \& Arcagök, S. (2021). Öğrenci projelerinin genellenebilirlik kuramı ile incelenmesi. Eğitimde Kuram ve Uygulama, 17(2), 69-78. doi: 10.17244/eku.1024532

Ethical Note: Research and publication ethics were followed. In this study, the data were collected before 2020, and voluntary participation of study group was observed during the data collection period. 


\title{
Öğrenci Projelerinin Genellenebilirlik Kuramı ile İncelenmesi
}

\author{
Durmuş Özbaş ${ }^{1}$, Serdar Arcagök ${ }^{2}$ \\ ${ }^{1}$ Eğitim Bilimleri Bölümü, Eğitim Fakültesi, Çanakkale Onsekiz Mart Üniversitesi, Çanakkale, Türkiye \\ dozbasi@gmail.com, ORCID:0000-0001-5078-477X \\ ${ }^{2}$ Temel Eğitim Bölümü, Ĕ̆itim Fakültesi, Çanakkale Onsekiz Mart Üniversitesi, Çanakkale, Türkiye \\ serdar arcagok21@,comu.edu.tr, ORCID: $\underline{0000-0002-4937-3268}$
}

\begin{abstract}
$\ddot{\mathbf{O z}}$
Öğrencilerin bilimsel araştırma yöntemlerini kullanarak bu konudaki becerilerinin artmasını sağlayan projeler aynı zamanda çok yönlü düşünme becerilerinin de gelişmesine olumu yönde katkı sağlamaktadır. Bu araştırmada öğretmen adaylarının hazırlamış oldukları projelerin bağımsız puanlayıcılar (jüriler) ile puanlanarak elde edilen ölçümlerin genellenebilirlik kuramı ile incelenmesi amaçlanmaktadır. Araştırma tarama modelinde tasarlanmıştır. Araştırmanın çalışma grubunda, 12 öğretim üyesi, 6 proje bulunmaktadır. Araştırmada kullanılan veri toplama aracı, proje hazırlamanın hedef ve kazanımları ile tutarlı olan TUBİTAK araştırma projelerinin değerlendirme ölçütleri kullanılmıştır. Her bir projeyi değerlendirecek olan jürilere her bir proje verilmiş olup, jüriler projeleri ilgili ölçütleri göz önünde bulundurarak puanlamışlardır. Her bir ölçüt için en düşük puan 1 en yüksek puan ise 4 olarak belirlenmiş olup, ölçme aracından toplam alınabilecek en yüksek puan ise 40 'tır.. Verilerin analizinde genellenebilirlik kuramı kullanılmış olup, Karar çalışması kapsamında da jüri sayısı sabit kalmak koşuluyla proje ve madde sayıları arttırılmış ve elde edilebilecek güvenirlik katsayıları olan G ve phi katsayıları incelenmiştir. Araştırma verilerinin analizinde genellenebilirlik kuramına dayalı analizlerin gerçekleştirildiği EduG 6.1 programı kullanılmıştır. Araştırmada puanlama işlemi yapan jüriler tüm projeleri puanladığı için tümüyle çaprazlanmış desen (jxpxm )kullanılmıştır. Araştırmadan elde edilen sonuçlardan biri; toplam varyansa en yüksek ikinci katkının değerlendirme ölçütü olarak kullanılan maddeler olmasıdır. Öğrencilerin projedeki başarısını değerlendirme amacıyla jüriler tarafından puanlanan maddeler toplam varyansa önemli ölçüde katkı sunmuștur.
\end{abstract}

\section{Makale Bilgisi}

Anahtar kelimeler: Araştırma projesi, genellenebilirlik kuramı, proje tabanlı öğrenme

Makale Geçmişi:

Geliş: 16 Kasım 2021

Düzeltme: -

Kabul: 4 Aralık 2021

Makale Türü: Araştırma Makalesi

\section{Examining Student Projects with Generalizability Theory}

\begin{abstract}
Projects that enable students to increase their skills in this subject by using scientific research methods also contribute positively to the development of multidimensional thinking skills. In this study, it is aimed to examine the measurements obtained by scoring the projects prepared by the pre-service teachers with independent raters (juries) with the theory of generalizability. The research was designed in the survey model. There are 12 faculty members and 6 projects in the study group of the research. The data collection tool used in the research and the evaluation criteria of TUBITAK research projects, which are consistent with the goals and achievements of project preparation, were used. Each project was given to the juries who would evaluate each project, and the juries scored the projects considering the relevant criteria. The lowest score for each criterion was determined as 1 and the highest score as 4 , and the highest total score that can be obtained from the measurement tool is 40 . Generalizability theory was used in the analysis of the data. G and phi coefficients, which are the reliability coefficients that can be increased and obtained, are examined. In the analysis of the research data, the EduG 6.1 program, which analyzes based on the generalizability theory, was used. Since the juries who made the scoring process in the research scored all the projects, a completely crossed design (jxpxm) was used. One of the results obtained from the research; The second highest contribution to the total variance is the items used as evaluation criteria. The items scored by the juries in order to evaluate the success of the students in the project contributed significantly to the total variance.
\end{abstract}

\section{Article Info}

Keywords: Generalizability theory, project-based learning, research project

Article History:

Received: 16 November 2021

Revised: -

Accepted: 4 December 2021

Article Type: Research Article 


\section{Extended Summary}

\section{Introduction}

Schools try to enhance students' cognitive skills such as language, mathematics and reading with traditional methods (WEF, 2016). On the other hand, schools have not been successful in developing students' skills such as critical and creative thinking, communication and cooperation in today's changing world (Shoning, 2017). In our age, that is defined as the fourth industrial revolution, projects may be an important tool in the development of these skills. Thus, students focus on learning via projects. One of the most important goals of student-centered education programs is to develop students' skills such as decision making, problem solving and focusing on learning effort nowadays. Projects have an important function in the development of these skills (Thomas, 2000). Thus, it contributes to the in-depth learning of students via an inquiring approach (Moursund, 2003). Project-based learning is an element that supports students' intrinsic motivation, self-efficacy and learning efforts compared to traditional approaches (Firdaus, Wahyudin, \& Herman, 2017). Barrows (1998) supported this point of view and discussed the project-based learning approach under three headings as constructing knowledge, supporting self-regulated learning and having lifelong learning motivation. Thus, students have the opportunity to manage their own learning, to overcome possible daily problems, and to experience the skills they have acquired. This also facilitates their preparation for their professional life.

Project-based learning approaches have great importance in providing students with the opportunity to experience the information they have learned and supporting their learning efforts (Brooks, 2013). In addition, it provides the opportunity for students to solve the problems they will encounter in daily life in classroom activities and to learn the perspectives of their peers in solving these problems (Kuhn, 2015). he improve one's skills via project applications depends on teacher behavior. As a matter of fact, teachers are expected to guide students support and guide them that encounter difficulties during project implementation(Hmelo-Silver, 2006). It is of great importance to determine whether the knowledge, skills, attitudes and habits acquired by the teacher candidates from the research project courses are realized at the expected level. It is thought that the research will contribute to the literature in this context. In addition, the fact that there is no study in which students' project work is evaluated with the theory of generalizability does not make the research crucial. In this respect, the problem of the research is to examine the measurements obtained by scoring the projects prepared by the pre-service teachers with independent raters (juries) with the theory of generalizability.

\section{Method}

In the study, the cross-sectional survey model, was used as a method. The most important feature of this model is that the data is obtained instantly with a single measurement (Fraenkel \& Wallen, 2003). In this study, it was considered to use this model since it was aimed to obtain the data obtained from the participants by measuring in one according to certain criteria. The study group of the research consists of faculty members $(n=12)$ who work in the "Research Project I" or "Research Project II" course in the preschool education department at six different universities in Turkey in the 2018-2019 academic year. Certain criteria were taken into account in determining the working group. These are a) attending research project courses for at least two semesters, b) participating in research voluntarily, c) serving as an executive in at least one scientific research project (BAP). The data collection tool is evaluation criteria of TUBITAK research project for this study. . That consistent with the goals and achievements of project preparation. Each project was given to the juries who would evaluate each project, and the juries scored the projects considering the relevant criteria. The lowest score for each criterion was determined as 1 and the highest score as 4 . The highest total score that can be obtained from the measurement tool is 40 . A total of 6 projects prepared by the students were included in the research. Student projects were evaluated by independent evaluators with 10 different criteria. The generalizability theory was used in the analysis of the data. In this study, too, 12 raters scored all projects using the specified evaluation criteria (items). Thus, all raters scored all projects included in the research. Within the scope of the decision study, the number of projects and items were increased, provided that the number of juries remained constant, and the reliability coefficients G and phi were examined. EduG 6.1 (Cardinet, Johnson, \& Pini, 2009) Analyzes based on generalizability theory were performed used in the analysis of the research. Since the juries who made the scoring process in the research scored all the projects, a completely crossed design (jxpxm) was used.

\section{Discussion and Conclusion}

In this research, the projects prepared by the students were handled in terms of jury, project and item. Thesewere examined within the framework of generalizability theory in a completely crossed design (jxpxm). In addition, a decision study was made in terms of the number of projects and items in terms of time, cost and practicality, and some results were reached in the light of the findings. The first of these results is related to the fact that there are similar scores to the 
projects in the scoring stage of the juries in the research. This result indicate that evaluators whose projects are evaluated and located in different places make a consistent evaluation process depending on the criteria.

Another result of the research is that the second highest contribution to the total variance is the items used as evaluation criteria. It contributed greatly to the total variance in the items scored by the juries in order to evaluate the success of the students in the project. In addition, the difficulty levels of the items were detected to be different from each other. In other words, students sometimes had difficulties while carrying out their projects. Similar findings were obtained by Özbaş1 and Arcagök (2019) on the examination of the same project with the multi-surface rasch model. In this context, it may be thought that students had difficulties in some situations while writing projects. Considering that preparing a project is a difficult and complex process (Katz \& Chard, 2000; MEB,2009), it is quite natural for students to have difficulties in some situations. In various studies indicate that, teacher candidates and teachers stated that they see themselves as inadequate or weak in writing projects. In this study, it can be seen as a very natural situation that teacher candidates have difficulties in writing projects in some cases. Because many pre-service teachers have not taken a course about project who are inexperienced about project preparation, may cause to difficulties in the projects hey prepare for the first time.

The generalizability and phi coefficients calculated based on the generalizability theory are calculated by proportioning the population variance to the observed variance (Brennan, 2001). In this study, the values of these coefficients were found to be significantly low. This may be caused to the scores obtained from the projects included in the research are close to each other.. Because generalizability coefficients are negatively affected by group homogeneity. In other words, as the similarity between groups increases, the variance value will decrease (Baykul, 2000). So,, the calculated generalizability and phi coefficients are found to be low. 


\section{Giriş}

Projeler, öğrencilerin ilgi duydukları alanlarla ilgili deneyim yaşadıkları, kendileri için önemli etkinlikler içeren bir süreç olarak tanımlanabilir (Fleming, 2000). Proje tabanlı öğrenme ise öğrenci ve öğretmenlerin bir ürünü veya etkinliği tamamlamak amacıyla işbirliğine dayalı olarak gerçekleştirdikleri yöntem olarak da ifade edilebilir (Darling-Hammond vd., 2008). Markham, Larner ve Lavitz (2003) proje tabanlı öğrenme sürecini öğrencilerin bilgi ve becerilerini karmaşık, otantik sorularla örülü dikkatlice tasarlanmış ürünlerle yapılandırmaları şeklinde tanımlamıştır. Fleming (2000) ise bu sürecin yapılandırmacı kuramla doğrudan ilişkili olduğunu savunmaktadır. Bu bağlamda proje tabanlı öğrenmelerin yapılandırmacı kuramı içeren ve öğrencilerin herhangi bir alanda edindikleri bilgileri deneyimlemelerine olanak sağlayan bütüncül öğretim uygulamaları olduğu düşünülebilir (Quigley, 2010). Bununla birlikte bireylerin edinmeleri gereken beceriler şeklinde belirtilen 21. Yüzyıl becerilerinin (World Economic Forum [WEF], 2016) öğrenciler tarafından benimsenmesi ve geliştirilmesinde proje tabanlı öğrenme yaklaşımları başat rol oynamaktadır (Harris, 2014). Okullar öğrencilerin dil, matematik ve okuma gibi bilişsel becerilerini geliştirmeyi geleneksel yöntemlerle gerçekleştirmeye çalışmaktadır (WEF, 2016). Buna karşın okullar, günümüz değişen dünyasında öğrencilerin eleştirel ve yaratıcı düşünme, iletişim ve işbirliği gibi becerilerini geliştirme konusunda hedeflenen başarıyı gösterememişlerdir (Shoning, 2017). Dördüncü sanayi devrimi olarak tanımlanan çağımızda projeler sözkonusu becerilerin geliştirilmesinde önemli bir araç olabilir. Nitekim projeler aracıllı̆ıyla öğrenciler öğrenmeye odaklanmaktadır. Öğrenci merkezli öğretim programlarının günümüzdeki en önemli amaçlarından biri de karar verme, problem çözme ve öğrenme çabasına odaklanma gibi becerilerinin öğrencilerde geliştirilmesidir. Bu becerilerin geliştirilmesinde projeler önemli bir işleve sahiptir (Thomas, 2000). Böylece öğrencilerin sorgulayıcı bir yaklaşımla derinlemesine öğrenmelerine katkıda bulunmaktadır (Moursund, 2003). Proje tabanlı öğrenmenin geleneksel yaklaşımlara göre öğrencilerin içsel motivasyonunu, öz yeterliklerini ve öğrenme çabalarını da destekleyen bir unsur olduğu söylenebilir (Firdaus, Wahyudin ve Herman, 2017). Barrows (1998) bu bakış açısını destekleyerek proje tabanlı öğrenme yaklaşımının bilgiyi yapılandırma, öz düzenlemeli öğrenmeyi destekleme ve yaşam boyu öğrenme motivasyonuna sahip olma şeklinde üç başlık altında ele almıştır. Böylece öğrenciler kendi öğrenmelerini yönetme, günlük olası problemlerin üstesinden gelme ve edindikleri becerilere deneyimle olanağı yakalamaktadır. Bu durum aynı zamanda onların mesleki yaşamlarına hazırlanmalarını kolaylaştırmaktadırlar.

Türkiye'de de dünyadaki gelişmelere paralel olarak eğitim alanında değişikliklere gidilmiştir. Türkiye'deki bu alanda gerçekleştirilen en önemli değişimlerden biri de yapılandırmacı yaklaşımı temel alan öğrenme merkezli, beyin temelli, sarmal ve tematik, beceri ve etkinlik merkezli model ve yöntemlerin eğitimde uygulanmasıdır (Güneş, 2012). Bunun yanı sıra Avrupa Yüksek Öğretim alanı içinde bulunan bireylerin daha kaliteli eğitim almalarını destekleyen ve yükseköğretim deneyimi yaşamalarını hedefleyen Bologna sürecine Türkiye'nin dahil olması eğitim alanında gerçekleştirilen değişimlerden biridir (YÖK, 2022). Bu çerçevede üniversite, enstitü ve fakültelerin bağlı bulunduğu Türkiye'deki eğitim fakültelerinde öğrenimlerini sürdüren öğretmen adaylarının çağın şartlarına göre daha donanımlı olarak yetiştirilmelerini sağlamak amacıyla lisans programları Yüksek Öğretim Kurumu (YÖK) tarafından 2007 tarihinde yenilenmiştir. Buna ek olarak YÖK tarafından okul öncesi lisans programlarına Araştırma Projesi I ve Araştırma Projesi II dersleri eklenmiştir. Bu derslerin temel amacının okul öncesi eğitim ile ilgili çeşitli konularda bilimsel araştırma projesi hazırlama, veri toplama ve gerçekleştirilen çalışmaların raporlaması olduğuna işaret edilmiştir (YÖK, 2022). Kuramsal çerçevede sunulan akademik eğitim çocukları pasif ve edilgin hale dönüştürürken, projelere katılım onları etkin, sorumluluk üstlenen ve üretken bir role büründürür (Katz ve Chard, 2000). Başka bir ifadeyle öğrenciler projeler aracılığıyla akademik alanda gelişim sergilerken aynı zamanda kendilerini birer birey ve öğrenen olarak daha iyi tanımaya başlarlar. Böylelikle bu durum çocukların merak duymalarını ve ilgi göstermelerini tetikler (Lev, Clarck ve Starkey, 2020). Öğrenciler yalnızca akademik olarak öğrenmekle kalmamakla birlikte aynı zamanda planlama, sorumluluk üstlenme, kendi fikirlerini uygulama ve çaba sarf etme gibi yaşam boyu öğrenme becerilerini de geliştirmektedirler (Harbaugh, 2020).

İlgili alan yazın incelendiğinde eğitim fakültesinde lisans programlarında verilen "Araştırma Projesi I" veya "Araştırma Projesi II" dersine yönelik gerçekleştirilen çalışmaların sınırlı olduğu ortaya çıkmıştır (Cengiz ve Karataş, 2014; Eti ve Gündoğdu, 2015; Özbaşı ve Arcagök, 2019). Cengiz ve Karataş (2014)'ın biyoloji öğretmenliği lisans programında öğrenim gören öğretmen adaylarının "Araştırma Projesi” dersine yönelik çalışmalarında öğretmen adaylarının bu derse yönelik olumlu tutum sergiledikleri saptanmıştır. Bunun yanı sıra öğretmen adaylarının eğitim araştırmalarına yönelik farkındalık kazandıkları ve güdülendiklerini belirttikleri ortaya çıkmıştır. Eti ve Gündoğdu (2015) tarafından gerçekleştirilen araştırmanın örneklemini ise okul öncesi öğretmenliği anabilim dalındaki dördüncü sınıfta öğrenimlerini sürdüren öğretmen adayları oluşturmaktadır. Bu araştırma bulguları ise öğretmen adaylarının proje yazma aşamaları konusunda beceri kazandıklarını vurguladıkları dikkat çekmiştir. Buna ek olarak araştırma konusunun belirlenmesi, dersin işlenişi, derse giren öğretim elemanları, dersin lisans programlarındaki yeri ve önemi hakkında öneriler sundukları saptanmıştır. Özbaşı ve Arcagök (2019) tarafından lisans düzeyinde dördüncü sınıfta öğrenimlerini sürdüren okul 
öncesindeki öğretmen adaylarıyla gerçekleştirilen çalışma ise "Araştırma Projesi II" dersi çok yüzeyli rasch analizi ile incelenmiştir. Araştırma sonucunda öğretmen adaylarının araştırma projesinin bazı uygulama basamaklarında zorlandıklarını ifade ettikleri saptanmıştır. Öğrencilere öğrendikleri bilgileri deneyimleme firsatı tanınmasında, onların öğrenme çabalarının desteklenmesinde proje tabanlı öğrenme yaklaşımları büyük önem taşımaktadır (Brooks, 2013). Bununla birlikte öğrencilerin sınıf içi etkinliklerde günlük yaşamda karşılaşacakları problemleri çözme olanağını yakalama ve bu problemlerin çözümünde akranlarının bakış açılarını öğrenme fırsatı sunmaktadır (Kuhn, 2015). Proje uygulamalarının öğrencilerde hedeflenen becerileri geliştirmesi öğretmen davranışına bağlıdır. Nitekim öğretmenlerin proje uygulamaları sırasında öğrencilere rehberlik etmeleri, onları desteklemeleri ve karşılaştıkları zorluklar karşısında onlara rehberlik etmeleri beklenmektedir (Hmelo-Silver, 2006). Öğretmen adaylarının araştırma projesi derslerinden edindikleri bilgi, beceri, tutum ve alışkanlıkların beklenen düzeyde gerçekleşip gerçekleşmediğinin tespit edilmesi büyük önem taşımaktadır. Araştırmanın bu bağlamda alanyazına katkıda bulunacağı düşünülmektedir. Ayrıca genellenebirlik kuramı ile öğrencilerin proje çalışmalarının değerlendirildiği herhangi bir çalışma olmaması da, araştırmayı önemli hale getirmemektedir. Bu yönüyle araştırmanın problemini, öğretmen adaylarının hazırlamış oldukları projelerin bağımsız puanlayıcılar (jüriler) ile puanlanarak elde edilen ölçümlerin genellenebilirlik kuramı ile incelenmesi oluşturmaktadır. Bu bağlamda araştırmanın amacı, öğrenci projelerinin puanlanmasında öğrenci, puanlayıcı (jüri) ve madde (ölçüt) etkileşimlerini de dikkate alarak, tümüyle çaprazlanmış desenin kullanıldığ durumlarda $\mathrm{G}$ ve phi katsayılarını genellenebilirlik kuramı çerçevesinde incelemektir. Bu genel amaç çerçevesinde aşă̆ıdaki sorulara yanıt aranmıştır:

1. Proje, puanlayıcı (jüri) ve madde (ölçüt) ile bunların etkileşimlerine ait kestirilen varyans bileşenleri nasildir?

2. Tüm değişkenlik kaynaklarının çaprazlanmış olduğu tümüyle çaprazlanmış desen (bxmxp) bağlamında farklı K çalışmaları için Hesaplanan G ve phi katsayıları ve mutlak hata değerleri nasıldır?

\title{
Yöntem
}

$\mathrm{Bu}$ bölümde araştırma modeli, çalışma grubu, veri toplama aracı ve veri analizi konularında bilgi verilmiştir. $\mathrm{Bu}$ çalışmada araştırma ve yayın etiğine uyulmuştur. Çalışmanın verileri 2020 yılı öncesi toplanmış olup, veri toplama sürecinde katılımcıların gönüllü katılımı gözetilmiştir.

\author{
Araştırma Modeli \\ Araştırmada genel tarama modellerinden kesitsel tarama modeli kullanılmıştır. Bu modelin en önemli özelliği verilerin \\ tek bir ölçümle anlık olarak elde edilmesidir (Fraenkel ve Wallen, 2003). Bu araştırmada katılımcilardan elde edilen \\ verilerin belirli ölçütlere göre tek seferde ölçüm yapılarak elde edilmesi amaçlandığından bu modelin kullanılması \\ düşünülmüştür.
}

\section{Çalışma Grubu}

Araştırmanın çalışma grubunu 2018-2019 öğretim yılında Türkiye'nin altı farklı üniversitesinde okulöncesi eğitimi anabilim dalında "Araştırma Projesi I" veya "Araştırma Projesi II" dersinde görev yapan öğretim üyeleri $(\mathrm{n}=12)$ oluşturmaktadır. Çalışma grubu belirlenmesinde belirli ölçütler dikkate alınmıştır. Bunlar a) araştırma projesi derslerine en az iki dönem girmek, b) araştırmaya gönüllü olarak katılmak, c) En az bir bilimsel araştırma projesinde ( BAP) yürütücü olarak görev yapmaktır.

\section{Veri toplama aracı}

Araştırmada kullanılan veri toplama aracı, proje hazırlamanın hedef ve kazanımları ile tutarlı olan TUBİTAK araştırma projelerinin değerlendirme ölçütleri kullanılmıştır. Her bir projeyi değerlendirecek olan jürilere her bir proje verilmiş olup, jüriler projeleri ilgili ölçütleri göz önünde bulundurarak puanlamışlardır. Her bir ölçüt için en düşük puan 1 en yüksek puan ise 4 olarak belirlenmiş olup, ölçme aracından toplam alınabilecek en yüksek puan ise 40 'tır. Öğrenciler tarafından hazırlanan toplam 6 proje araştırmaya dahil edilmiştir. Öğrenci projeleri bağımsız değerlendiriciler tarafından 10 farklı ölçüt ile değerlendirilmiştir. Veri toplama aracında kullanılan ölçütler tablo 1'de verilmiştir. 
Tablo 1. Veri toplama arac1

\begin{tabular}{|c|c|c|c|}
\hline & Ölçüitler & & puan \\
\hline & 2 & 3 & 4 \\
\hline Proje başlığı & $\begin{array}{ll}\text { Proje başlığının içerikle proje başlığı içeriği } \\
\text { hiç ilgisi yoktur } & \text { kısmen karşılamaktadır }\end{array}$ & $\begin{array}{l}\text { proje başlığı içeriği } \\
\text { yansıtmaktadır ancak } \\
\text { yazım kurallarına } \\
\text { uygun değil }\end{array}$ & $\begin{array}{l}\text { proje başlı̆̆ içerikle } \\
\text { uyumludur. }\end{array}$ \\
\hline
\end{tabular}

\begin{tabular}{|c|c|c|c|c|c|}
\hline Proje Özetini Yazabilme & $\begin{array}{l}\text { Özet projenin yöntem, } \\
\text { bulgular ve sonuç } \\
\text { bölümlerini } \\
\text { karşılamamaktadır. }\end{array}$ & $\begin{array}{l}\text { Özetin amaç, yöntem, } \\
\text { bulgular ve } \\
\text { bölümlerinde } \\
\text { eksiklikler var. }\end{array}$ & $\begin{array}{l}\text { Amaç, } \\
\text { bulgular ve } \\
\text { bölümleri } \\
\text { ancak } \\
\text { eksiklikler var }\end{array}$ & $\begin{array}{r}\text { yöntem, } \\
\text { sonuç } \\
\text { verilmiş } \\
\text { k1smen } \\
\text { r. }\end{array}$ & $\begin{array}{lr}\text { Amaç, yöntem, } \\
\text { bulgular ve } \\
\text { siralı vonuç } \\
\text { uygun bir şeriğe } \\
\text { verilmiş. }\end{array}$ \\
\hline
\end{tabular}

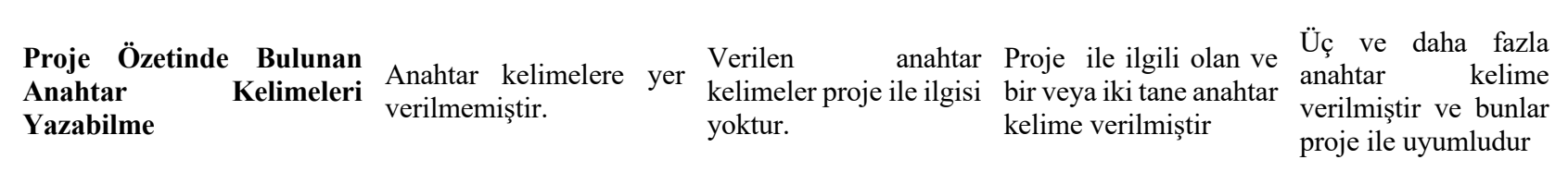

\begin{tabular}{|c|c|c|c|c|c|c|}
\hline $\begin{array}{l}\text { Projenin } \\
\text { Çerçevesini } \\
\text { Düzenleyebilme }\end{array}$ & Kuramsal & $\begin{array}{l}\text { Projenin } \\
\text { çerçevesi } \\
\text { alınmamıştır. }\end{array}$ & $\begin{array}{r}\text { kurumsal } \\
\text { ele }\end{array}$ & $\begin{array}{l}\text { Projenin kurumsal } \\
\text { çerçevesi ele alınmış } \\
\text { ancak araştırma konusu } \\
\text { ile birleştirilmemiştir. }\end{array}$ & $\begin{array}{l}\text { Kurumsal çerçeve ele } \\
\text { alınmıştır ancak yeterli } \\
\text { değildir. }\end{array}$ & $\begin{array}{l}\text { Kurumsal çeç̧eve } \\
\text { tamamen projenin } \\
\text { içeriği ile uyumlu } \\
\text { olup yeterli düzeyde } \\
\text { ele alınmıştır. }\end{array}$ \\
\hline
\end{tabular}

\begin{tabular}{|c|c|c|c|c|c|}
\hline $\begin{array}{l}\text { Projenin Özgün } \\
\text { Yazabilme }\end{array}$ & Değerini & $\begin{array}{l}\text { Projenin özgün değerine } \\
\text { hiç değinilmemiştir. }\end{array}$ & $\begin{array}{l}\text { Yazılan özgün değer } \\
\text { projenin içeriği ile } \\
\text { uyumlu değildir. }\end{array}$ & $\begin{array}{l}\text { Projenin özgün değeri } \\
\text { yazılmiştır } \\
\text { yeterli } \\
\text { değildir. }\end{array}$ & $\begin{array}{l}\text { Özgün değer } \\
\text { tamamen projenin } \\
\text { içeriği ile uyumlu } \\
\text { olup yeterli düzeyde } \\
\text { ele alınmıştır. }\end{array}$ \\
\hline
\end{tabular}

\begin{tabular}{|c|c|c|c|c|}
\hline $\begin{array}{l}\text { Projenin } \\
\text { Belirleyebilme }\end{array}$ & $\begin{array}{l}\text { Projenin yöntemine hiç } \\
\text { değinilmemiştir. }\end{array}$ & $\begin{array}{l}\text { Projenin yöntemine } \\
\text { değinilmiştir ancak } \\
\text { içerikle } \\
\text { uyuşmamaktadır. }\end{array}$ & 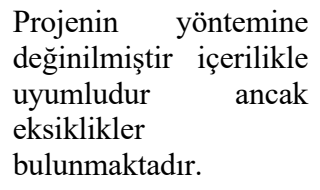 & $\begin{array}{l}\text { Projenin yöntemine } \\
\text { değinilmiştir } \\
\text { içerilikle de } \\
\text { uyumludur. }\end{array}$ \\
\hline $\begin{array}{l}\text { Projenin Etkinlik takvimini } \\
\text { Belirleyebilme }\end{array}$ & $\begin{array}{l}\text { Proje etkinlik takvimine } \\
\text { değinilmemiştir. }\end{array}$ & $\begin{array}{lr}\text { Proje } & \text { etkinlik } \\
\text { takviminde } & \text { ciddi } \\
\text { eksiklikler } & \\
\text { bulunmaktadir. } & \end{array}$ & $\begin{array}{l}\text { Proje etkinlik } \\
\text { takviminde bazı (bir ya } \\
\text { da birkaç etkinlikte) } \\
\text { eksiklikler } \\
\text { bulunmaktadır }\end{array}$ & $\begin{array}{l}\text { Etkinlik takvimi } \\
\text { projeyle tutarlıdır. }\end{array}$ \\
\hline $\begin{array}{l}\text { Projeden Beklenen Yaygin } \\
\text { Etkiyi Belirtebilme }\end{array}$ & $\begin{array}{l}\text { Projeden beklenen yaygın } \\
\text { etki belirtilmemiştir. }\end{array}$ & \begin{tabular}{lr}
\multicolumn{1}{c}{ Projeden } & beklenen \\
yaygın etki & proje \\
amacindan & oldukça \\
uzaktır.
\end{tabular} & $\begin{array}{l}\text { Projeden } \\
\text { yaygın etki } \begin{array}{l}\text { beklenen } \\
\text { düzeyde }\end{array} \\
\text { açıklanmamıştır }\end{array}$ & $\begin{array}{l}\text { Beklenen yaygın etki } \\
\text { proje hedefleriyle } \\
\text { tutarlıdır. }\end{array}$ \\
\hline $\begin{array}{l}\text { Projenin Genel Bütçe } \\
\text { Tablosunu Oluşturabilme }\end{array}$ & $\begin{array}{l}\text { Projenin genel bütçe } \\
\text { tablosu } \\
\text { oluşturulmamıştır. }\end{array}$ & $\begin{array}{l}\text { Projenin genel bütçe } \\
\text { tablosu proje içeriğinin } \\
\text { dışındadır. }\end{array}$ & $\begin{array}{l}\text { Projenin genel bütçe } \\
\text { tablosunda eksiklikler } \\
\text { bulunmaktadır. }\end{array}$ & $\begin{array}{l}\text { Projenin } \\
\text { tablonel bütçe } \\
\text { tutarlıdır. }\end{array}$ \\
\hline $\begin{array}{l}\text { Proje Bütçesini } \\
\text { Gerekçelendirebilme }\end{array}$ & $\begin{array}{l}\text { Proje bütçesi } \\
\text { gerekçelendirilmemiştir. }\end{array}$ & $\begin{array}{lr}\text { Proje bütçesi } & \text { proje } \\
\text { hedefleriyle } & \text { tutarlı } \\
\text { değildir. } & \end{array}$ & $\begin{array}{l}\text { Proje bütçesinde bazı } \\
\text { eksiklik veya } \\
\text { yanlışlıklar vardır. }\end{array}$ & $\begin{array}{l}\text { Proje bütçesi projeyle } \\
\text { tutarlıdır. }\end{array}$ \\
\hline
\end{tabular}

\section{Veri analizi}

Araştırmanın veri analizinde genellenebilirlik kuramı kullanılmıştır. Genellenebilirlik kuramı, ölçme sonucu gözlenen puanlardaki tutarsızlığın kaynaklarının incelenmesine ve değerlendirilmesine imkan veren, klasik test kuramına alternatif olarak ortaya çıkan istatistiksel bir analizdir (Brennan, 2001; Cronbach, Gleser, Nanda ve Rajaratnam, 1972). Genellenebilirlik kuramı herhangi bir araştırmadan elde edilen ölçme sonuçlarının genelleme yapılacak evrene uygun 
olup olmadığını, ne ölçüde genelleme yapılabileceği hakkında bilgi vermektedir (Şencan, 2005). Bu işlemi yaparken ölçme sonuçlarına karışabilecek tüm hata kaynaklarını, klasik test kuramının aksine, ayrı ayrı ele alır ve bu hata kaynaklarının etkileşimlerini inceler (Brennan, 2001; Shavelson ve Webb 1991). Genelebilirlik kuramı ile iki işlem çok daha kolay bir şekilde gerçekleştirilebilmektedir. Bunlar ölçme işleminin niteliğini değerlendirmek, diğeri ise, ölçmese sonuçlarına dayalı olarak niteliğin nasıl arttırabileceğini hakkında bazı olası durumları kullanarak tahminler yapmak. $\mathrm{Bu}$ işlem için genellenebilirlik çalışması (g) ve karar (D) çalışmaları yapılmaktadır. Genellenebilirlik çalışması (g), araştırma söz konusu olan desendeki her bir değişkenlik kaynağ1 ve bu değiş̧kenlik kaynaklarının etkileşimleri için varyans bileşenlerini hesaplar (Brennan, 2000). Karar çalışmasında (D) ise $G$ çalışması sonuçlarına dayalı olarak farklı durumların etkililiğini tahmin ederek hata değerini en aza indirebilecek senaryoyu amaçlamaktadır (Pedersen, Hagtvet ve Karterud, 2007). Bu şekilde araştırmacı elindeki ölçme sonuçlarına dayalı olarak, farklı sonuçlar hakkında da bilgi sahibi olabilmektedir.

$\mathrm{Bu}$ çalışmada da, 12 puanlayıcı tüm projeleri belirtilen değerlendirme kriterleri (maddeler) kullanarak puanlamışlardır. Böylece tüm puanlayıcılar araştırmada yer alan tüm projeleri puanlamıştır. Karar çalışması kapsamında da jüri sayısı sabit kalmak koşuluyla proje ve madde sayıları artırılmış ve elde edilebilecek güvenirlik katsayıları olan $\mathrm{G}$ ve phi katsayıları incelenmiştir. Araştırma verilerinin analizinde genellenebilirlik kuramına dayalı analizlerin gerçekleştirildiği EduG 6.1 (Cardinet, Johnson ve Pini, 2009) programı kullanılmıştır. Araştırmada puanlama işlemi yapan jüriler tüm projeleri puanladığı için tümüyle çaprazlanmış desen (jxpxm )kullanılmıştır.

\section{Bulgular}

Araştırmada 12 jüri , 6 proje ve 10 madde kullanılarak gerçekleştirilen iki yüzeyli tümüyle çaprazlanmış çaprazlanmış desene ilişkin ANOVA sonuçları tablo 2'de verilmiştir.

Tablo 2. İki yüzeyli Proje Değerlendirme ölçüm sonuçlarına ilişkin hesaplanan ANOVA sonuçları

\begin{tabular}{|c|c|c|c|c|c|c|c|}
\hline $\begin{array}{l}\text { Değişkenlik } \\
\text { Kaynağı }\end{array}$ & Kareler Toplam 1 & sd & Kareler Ortalamas 1 & $\begin{array}{l}\text { Kestirilen } \\
\text { Değeri }\end{array}$ & Varyans & $\begin{array}{l}\text { Toplam } \\
\text { Yüzdesi }\end{array}$ & Varyans \\
\hline Jüri (j) & 28.24861 & 11 & 2.56806 & 0.00408 & & 0.5 & \\
\hline Proje (p) & 5.95694 & 5 & 1.19139 & 0.00368 & & 0.4 & \\
\hline Madde (m) & 173.42917 & 9 & 19.26991 & 0.23758 & & 28.4 & \\
\hline jp & 31.99306 & 55 & 0.58169 & 0.03268 & & 3.9 & \\
\hline $\mathrm{jm}$ & 197.65417 & 99 & 1.99651 & 0.29026 & & 34.7 & \\
\hline $\mathrm{pm}$ & 19.02917 & 45 & 0.42287 & 0.01400 & & 1.7 & \\
\hline jpm, e & 126.18750 & 495 & 0.25492 & 0.25492 & & 30.4 & \\
\hline Toplam & 582.49861 & 719 & & & & $100 \%$ & \\
\hline
\end{tabular}

Tablo 2'de verilen bilgilere göre, jürilere ait varyans bileşenin değeri 0.0041 'dir. Toplam varyansa katkısı da \%0.5 gibi en küçük ikinci değerdir. Evren puanı açısından bu varayns bileşeni, bireyleri jürilerin birbirinden sistematik bir şekilde ayrılmadığı ya da başka bir ifade ile farklılık göstermediğini ifade etmektedir.

Proje varyans bileşeni için hesaplanan varyans değeri en düşük (0.0036) varyans etkisine sahiptir. Toplam varyansa katkısı ise en düşük değer olan \% 0,4'tür. Bu değer de araştırmadaki projelerin birbirine oldukça yakın veya benzer olduğunu, aralarında farklılığın çok az olduğunu göstermektedir.

Madde varyans bileşeni için elde edilen değer ise 0.23758 ile bu araştırmada elde edilen en yüksek ikinci bileşendir. Toplam varyansın da \%28,4'ünü açıklamaktadır. Buna göre, proje değerlendirme amacıyla oluşturulan bu maddelerin birbirinden farklı durum ve özellikleri ölçebildiği ve sistematik bir şekilde farklılık gösterdiği ifade edilebilir. Ayrıca bu durum, ölçüt maddelerinin birbirinden farklı güçlük düzeylerine sahip olduğu göstermektedir.

Jüri-proje varyans bileşeni için hesaplanan değer 0.03268 olup toplam varyansa katkısı da \%3,9'dur. Bu varyans bileşeninden elde edilen değerlere göre, jüriler her projeye farklı bir puan vermiş olduğunu göstermekle birlikte, projelerin toplam puanlarının birbirinden farkları odluğunu işaret etmektedir.

Jüri-madde etkileşimine dayalı olarak hesaplanan varyans bileşeni değeri 0.29026 ile en büyük varyans bileşeni değerine sahiptir. Toplam varyansa katkısı da \%34,7 ile en yüksek değerdir. Bu değer jürilerin verdikleri puanların her 
maddede farklılık gösterdiğini, bir başka ifadeyle bir jürinin yüksek puan verdiği bir maddeye başka bir jüri düşük puan vermiştir.

Proje-madde etkileşimi için hesaplanan varyans değeri ise 0,01400 olarak elde edilmiştir. Toplam varyansa katkısı ise \%1,7' dir. Bu değer, projelerde yer alan maddelerin her projede aldıkları değerlerin birbirinden hangi oranda farklı olduğunu göstermektedir.

Tablo 2'de verilen son varyans değeri, artık bileşenine aittir. Bu bileşene ait varyans değeri 0,25492 ve toplam varyansa katkısı da \%30,4'tür. Bu varyans bileşeni değeri, jüri, proje ve maddeler arasındaki etkileşim ile bu çalışmada ölçülemeyen sistematik olmayan değişkenlik kaynaklarının varlığının bir göstergesidir.

Öğrencilerin projelerinin değerlendirilmesine ilişkin elde edilen puanların jxpxm deseninde proje ve madde sayılarının değiştirilmesi ile oluşturulmuş karar çalışmasına ilişkin elde edilen bulgular tablo3'te verilmiştir.

Tablo 3. Farklı K çalışmaları için Hesaplanan göreli " $\sigma^{2}(\delta)$ ” ve mutlak hata " $\sigma^{2}(\Delta)$ ” değerleri

$$
\text { Proje Sayıları }
$$

\begin{tabular}{lllllll} 
Maddeler & $\mathbf{n p}=\mathbf{1 0}$ & & $\mathbf{n p = 1 2}$ & & $\mathbf{n p = 1 8}$ \\
\cline { 2 - 7 } & $\sigma^{2}(\delta)$ & $\sigma^{2}(\Delta)$ & $\sigma^{2}(\delta)$ & $\sigma^{2}(\Delta)$ & $\sigma^{2}(\delta)$ & $\sigma^{2}(\Delta)$ \\
$\mathbf{n}_{\mathbf{m}}=\mathbf{1 0}$ & 0,035 & 0,059 & 0,033 & 0,058 & 0,032 & 0,056 \\
$\mathbf{n}_{\mathbf{m}}=\mathbf{2 0}$ & 0,019 & 0,031 & 0,018 & 0,031 & 0,017 & 0,029 \\
$\mathbf{n}_{\mathbf{m}}=\mathbf{2 5}$ & 0,015 & 0,025 & 0,015 & 0,025 & 0,014 & 0,023 \\
\hline
\end{tabular}

Tablo 3'teki bulgulara göre, ölçme aracındaki madde sayısı arttıç̧a göreli ve mutlak hata varyansları da düşmektedir. Araştırmada kullanılan proje sayıları arttırıldığında da benzer şekilde göreli ve mutlak hata varyanslarının azaldığı bulunmuştur.

Tablo 4. Farklı K çalışmaları içim Hesaplanan G ve phi katsayıları

\begin{tabular}{|c|c|c|c|c|c|c|c|c|}
\hline \multirow{3}{*}{ Maddeler } & \multicolumn{8}{|c|}{ Proje Sayıları } \\
\hline & \multicolumn{2}{|l|}{$n p=6$} & \multicolumn{2}{|c|}{$n p=10$} & \multicolumn{2}{|l|}{$n p=12$} & \multicolumn{2}{|c|}{$n p=18$} \\
\hline & $\mathrm{G}$ & Phi & $\mathrm{G}$ & Phi & $\mathrm{G}$ & Phi & $\mathrm{G}$ & Phi \\
\hline $\mathbf{n}_{\mathrm{m}}=\mathbf{1 0}$ & 0,095 & 0,061 & 0,1 & 0,065 & 0,11 & 0,066 & 0,11 & 0,068 \\
\hline $\mathbf{n}_{\mathrm{m}}=\mathbf{2 0}$ & 0,16 & 0,11 & 0,18 & 0,12 & 0,18 & 0,12 & 0,19 & 0,12 \\
\hline$n_{m}=25$ & 0,18 & 0,12 & 0,2 & 0,14 & 0,21 & 0,14 & 0,23 & 0,15 \\
\hline
\end{tabular}

Tablo 4'te, jüri sayısı sabit kalmak koşuluyla farklı sayıda proje ve madde sayıları oluşturularak edle edilen G ve phi katsayıları verilmiştir. G ve phi katsayıları evre puan varyansının gözlenen puan varyansına oranı alınarak elde edilmektedir. Buna göre, değerlendirmede kullanılan madde sayıları arttırıldığında, hem G hem de phi katsayıları belli bir düzeyde artmaktadır.

\section{Sonuç, Tartışma ve Öneriler}

$\mathrm{Bu}$ araştırmada öğrencilerin hazırlamış oldukları projelerin jüri, proje ve madde bakımından ele alınarak tümüyle çaprazlanmış desende (jxpxm) genellenebilirlik kuramı çerçevesinde incelenmiştir. Ayrıca, zaman, maliyet ve pratiklik açısından proje ve madde sayıları bakımından karar çalışması da yapılmış ve elde edilen bulgular ışığında bazı sonuçlara ulaşılmıştır. Bu sonuçlardan birincisi, araştırmada yer alan jüriler puanlama aşamasında projelere benzer puanlar olduğu ile ilgilidir. Bu durum, projeleri değerlendirilen ve birbirinden farklı yerlerde bulunan değerlendiricilerin ölçütlere bağlı olarak ve tutarlı bir değerlendirme işlemi yaptıklarını göstermektedir.

Araştırmadan elde edilen diğer bir sonuç ise, toplam varyansa en yüksek ikinci katkının değerlendirme ölçütü olarak kullanılan maddeler olmasıdır. Öğrencilerin projedeki başarısını değerlendirme amacıyla jüriler tarafından puanlanan maddelerde toplam varyansa önemli ölüde katkı sunmuştur. Ayrıca maddelerin güçlük düzeyleri birbirinden de farklı bulunmuştur. Bir başka ifadeyle öğrenciler Projelerini gerçekleştirirken bazen zorlandıklarını da belirtmek çok da yanlış olmayacaktır. Özbaş1 ve Arcagök (2019) tarafından yapılan aynı projenin çok yüzeyli rasch modeli ile incelenmesi konulu araştırma sonuçlarında da benzer bulgular elde edilmiştir. Bu bağlamda, öğrenciler proje yazarken 
bazı durumlarda zorlandıklarını belirtmek çok da yanlış olmayacaktır. Proje hazırlamanın zor ve karmaşık br süreç (Katz ve Chard, 2000; MEB,2009) olduğu göz önüne alındığında öğrencilerin bazı durumlarda zorlanmaları olukça doğal bir durumdur. Gerçekleştirilen çeşitli araştırmalarda Öğretmen adayları ve öğretmenler proje yazma konusunda kendilerini yetersiz veya zayıf gördüklerini belirtmişlerdir. Bu araştırmada da öğretmen adaylarının proje yazma konusunda bazı durumlarda zorlanmaları oldukça doğal bir durum olarak karşılanabilir. Çünkü birçok öğretmen adayı proje hazırlama ile ilgili daha önceden ders almamış olması ve bu konuda deneyimsiz olmaları, ilk kez hazırladıkları projelerde zorlanabilirler.

Genellenebilirlik kuramına dayalı olarak hesaplanan genellenebilirlik ve phi katsayısıları, evren varyansını gözlenen varyansa oranlayarak hesaplanmaktadır (Brennan, 2001). Bu araştırmada elde edilen bu katsayılara ilişkin değerlerin önemli ölçüde düşük olarak bulunmuştur. $\mathrm{Bu}$ durum araştırmaya dahil olan projelerden elde edilen puanların birbirine yakın olması ile açıklanabilir. Çünkü genellenebilirlik katsayıları grup benzeşikliğinden olumsuz yönde etkilenmektedir. Baka bir ifadeyle, grupların birbirine benzerliği arttıkça varyans değeri düşücek (Baykul, 2000, bu durumda hesaplanan genellenebilirlik ve phi katsayılarının düşük bulunmasına neden olduğu söylenebilir.

Araştırmadan elde edilen sonuçlara göre bazı önerilerde bulunulabilir. Bu önerilerden birincisi, proje değerlendirme konusunda jürilere nasıl değerlendirme ve puanlama yapılacağına ilişkin bir bilgilendirme yapılabilir. Bu konuda farklı öğrenci gruplarında proje hazırlama ile ilgili akran ve uzman değerlendirmeleri yapılmasına olanak verilerek elde dilen ölçme sonuçlar genellenebilirlik kuramı çerçevesinde incelenebilir.

Yazarlar çalışmaya eşit oranda katkı sunmuşlardır.

\section{Araştırmacıların Katkı Oranı}

Destek ve Teşekkür

Bu makale Çanakkale Onsekiz Mart Üniversitesi Bilimsel Araştırma Projeleri (BAP) Birimi tarafından SBA-2019-2920 Nolu proje ile desteklenmiştir. Yazarlar Çanakkale Onsekiz Mart Üniversitesi BAP birimine teşekkür etmektedirler.

\section{Çıkar Çatışması}

Yazarlar çalışmada herhangi bir çıkar çatışmasının bulunmadığını beyan etmişlerdir.

\section{Kaynakça / References}

Barrows, H.S. (1998). The essentials of problem-based learning. J Dent Educ, 62(9), 630-632.

Berkson, L. 1993. Problem-based learning: Have the expectations been met. Academic Medicine, 68, 79-88.

Brennan, R. L. (2001). Generalizability theory. New York: Springer- Verlog.

Brooks, J. G. (2013). Constructivism: Transforming knowledge of how people learn into meaningful instruction., The handbook of educational theories (pp. 271-275). Charlotte, NC: Information Age Publishing, Inc.

Cardinet, J., Johnson, S., \& Pini, G. (2009). Applying generalizability theory using EduG. New York: Routledge.

Cengiz, C. ve Karataş, F.Ö. (2014). Alan eğitiminde araştırma projesi dersi: biyoloji öğretmen adaylarının yansıtmaları. Eğitim ve Öğretim Araştırmaları Dergisi, 3(4), 51-58.

Darling-Hammond, L., Barron, B., Pearson, P., Schoenfeld, A., Stage, E., Zimmerman, T., Cervetti, G., \& Tilson, J. (2008). Powerful learning. San Francisco, CA: Jossey-Bass.

Eti, İ. ve Gündoğdu, S. (2016). Okul öncesi öğretmenliği dördüncü sınıf öğrencilerinin araştırma projesi dersine ilişkin görüş ve önerileri. Abant İzzet Baysal Üniversitesi Ĕgitim Fakültesi Dergisi, 16 (1), ss:121-139.

Firdaus, F. M., Wahyudin, \& Herman, T. (2017). Improving primary students' mathematical literacy through problem based learning and direct instruction. Educational Research and Reviews, 12(4), 212-219.

Fleming, D. S. (2000). A teacher's guide to project-based learning. West Virginia: AEL.

Fleming, D. S. (2000). A Teacher's guide to project-based learning. Scarecrow Education, Blue Ridge Summit, PA 
Fraenkel, J. R., \& Wallen, N. E. (2003). How to design and evaluate research in education (5th ed.). Boston: McGrawHill.

Güneş, F. (2012). Bologna süreci ile yükseköğretimde öngörülen beceri ve yetkinlikler. Yüksekögrretim ve Bilim Dergisi, (1), 1-9.

Harbaugh, S. (2020). Project-based learning: Is it worth it. Unpublished master thesis. Department of Teacher Education and Human Performance College of Education and Health Sciences, Minot State University, North Dakota.

Harris, M. J. (2015). The challenges of implementing project-based learning in middle schools. University of Pittsburgh.

Hmelo-Silver, C. (2006). Design principles for scaffolding technology-based inquiry. Collaborative reasoning, learning and technology (pp. 147-170). Mahwah, NJ: Erlbaum.

Katz, L. G., \& Chard, S. C. (2000). Engaging children's minds: The project approach (2nd ed.). Stamford, CT: Ablex.

Kuhn, D. (2015). Thinking together and alone. Educational Researcher, 44(1), 46-53

Lev, S., Clarck, A. \& Starkey, E. (2020). Implementing project based learning in early childhood: Overcoming misconceptions and reaching success. Newyork: Routledge.

Markham, T., Larner, J., \& Ravitz, J. (2003). Project-based learning handbook: A guide to standards focused projectbased learning for middle and high school teachers. Novato, CA: Buck Institute of Education.

Moursund, D. G. (2003). Project-based learning using information technology (2nd ed.). Eugene, OR: International Society for Technology in Education.

Ozbasi, D. \& Arcagok, S. (2019). An investigation of pre- service preschool teachers' projects using the many-facet rasch model. International Journal of Progressive Education, 15(4), 157-173.

Quigley, D. (2010). Project-based learning and student achievement. ProQuest, UMI Dissertations Publishing.

Shoning, M. (2017). This is the one skill your child needs for the jobs of the future. World Economic Forum. https://www.weforum.org/agenda/2017/09/skills-children-need-work-future-play-lego/

Pedersen, G., Hagtvet, K. A., and Karterud, S. (2007). generalizability studies of the global assessment of functioningsplit version. Comprehensive Psychiatry, 48, 88- 94.

Shavelson, J. R., and Webb, N. M. (1991). Generalizability theory: A primer. Newbury Park. CA: Sage Publications.

Şencan, H. (2005). Sosyal davranışsal ölçümlerde güvenirlik ve geçerlilik. Ankara: Seçkin yayıncılık.

Thomas, J. W. (2000). A review of research on project-based learning. San Rafael, CA: Autodesk Foundation.

WEF (2016). Word Economic Forum, The Future of Jobs, Switzerland: WEF, 2016.

YÖK (2007). Yüksek Öğretim Kurumu. Eğitim fakültesi öğretmen yetiştirme lisans programları Ankara.

YÖK (2022). Yüksek Öğretim Kurumu Uluslararası İlişkiler Başkanlığı.https://uluslararasi.yok.gov.tr/uluslararasilasma/bologna/temel-bilgiler/bologna-sureci-nedir. Erişim Tarihi : [ 12.03.2021]. 